\title{
Subject is Randomized
}

National Cancer Institute

\section{Source}

National Cancer Institute. Subject is Randomized. NCI Thesaurus. Code C114209.

A status indication that a subject is already assigned to an arm of a clinical trial by chance. 